\title{
PERFIL SOCIOECONÔMICO DA AVICULTURA NO SETOR PRIMÁRIO DO ESTADO DO AMAZONAS, BRASIL
}

\author{
Frank George Guimarães Cruz* \\ João Paulo Ferreira Rufino** \\ Ramon Duque Melo*** \\ Julmar da Costa Feijó*** \\ Jessica Lima Damasceno***** \\ Ana Paula Guimarães Cruz Costa****
}

RESUMO: Este trabalho teve como objetivo realizar o diagnóstico da estrutura do setor avícola no Estado do Amazonas. Foram utilizadas técnicas de avaliação para verificar o foco dos investimentos e os retornos obtidos por este setor na economia do Estado através de levantamentos de dados de órgãos públicos estaduais e federais e aplicação de questionário e visitas nos estabelecimentos avícolas. Os resultados expressaram que o Estado do Amazonas possui produção amplamente direcionada ao segmento de postura, atividade esta desenvolvida principalmente no município de Manaus e regiões metropolitanas contando com plantéis produtivos mesmo com a dependência de importação de matérias-primas utilizadas na fabricação das rações. A avicultura de corte, em contrapartida, praticamente inexiste em escala industrial. Esta lacuna de mercado é preenchida pela ascendente avicultura caipira que apresenta participação efetiva na economia do Estado, tanto por sua produção quanto pelo seu contexto social e apelo agroecológico do sistema de manejo caipira, fatores que denotam atenção devido às políticas de incentivo à produção sustentável no Estado.

PALAVRAS-CHAVE: Amazônia; Caipira; Contexto Social; Postura; Setor Primário.

Doutor em Biotecnologia pela Universidade Federal do Amazonas (UFAM); Docente Associado IV, Coordenador do Programa de Pós-Graduação em Ciência Animal e do Setor de Avicultura da Faculdade de Ciências Agrárias Universidade Federal do Amazonas (UFAM), Brasil; E-mail: frankgcruz@gmail.com

** Mestrando no Programa de Pós-Graduação em Ciência Animal na Universidade Federal do Amazonas (UFAM), Brasil.

*** Discentes de graduação em Zootecnia pela Universidade Federal do Amazonas (UFAM); Bolsistas de Iniciação Científica do CNPq, Brasil.

**** Mestranda no Programa de Pós-Graduação em Zootecnia (PPZ) pela Universidade Estadual do Oeste do Paraná (UNIOESTE), Brasil.

${ }^{* * * * *}$ Discente de graduação em Zootecnia pela Universidade Federal do Amazonas (UFAM), Brasil. 


\section{SOCIO-ECONOMIC PROFILE OF FOWL BREEDING IN THE STATE OF AMAZONAS, BRAZIL}

ABSTRACT: The structure of the fowl breeding sector in the state of Amazonas is diagnosed. Evaluation techniques verified the investments and profits by this sector within the state's economy through data retrieved from state and federal public organs, coupled to a questionnaire and visits to avian enterprises. Results showed that the state of Amazonas mainly features egg-production and the activity lies in the municipality of Manaus and metropolitan regions, with productive broodstocks even though prime matter for diet production is imported. On the other hand, broilers are practically not extant on an industrial scale. The gap in the market is occupied by a rise in country chicken with interesting participation in the state's economy in production and in the social aspect with an agro-ecological appeal for country chicken management. These factors reveal special care due to incentive policies to sustainable production in the state.

KEY WORDS: Amazonas; Country Chicken; Social Context; Egg-Laying; Primary Sector.

\section{INTRODUÇÃO}

A partir da década de 1980 foi possível observar mudanças no ambiente macro econômico mundial a partir da globalização dos mercados. No Brasil, em especial, este fenômeno e a estabilização da economia impulsionaram o acirramento da competitividade interna, em razão das politicas de incentivo às importações e da entrada de toda uma diversidade de produtos a preços menores e de qualidade superior. A estabilização da economia trouxe problemáticas quanto aos ganhos financeiros oriundos do mercado especulativo e demandou esforços representativos das empresas, direcionados à obtenção de lucros por intermédio de ganhos produtivos (PEREIRA, 2003).

Neste contexto, as unidades federativas que compõem a Amazônia Legal (Estados do Acre, Amazonas, Amapá, Pará, Rondônia, Roraima, Tocantins e partes dos Estados do Maranhão e do Mato Grosso) sempre se caracterizaram pela baixa participação no Produto Interno Bruto do país. Considerando em particular a região 
Norte, a mesma alcançou apenas cerca de 5\% de participação no PIB, cifra que Estados como Rio Grande do Sul e Paraná superam com grande folga. Em nível de unidades federativas da Amazônia Legal, destacam-se os Estados do Pará, Amazonas e Mato Grosso, com maior participação, sendo que o município de Manaus, em particular, ainda concentra o quarto PIB municipal e o terceiro em renda per capita do país (IBGE, 2013).

A aceleração do setor primário do Estado do Amazonas, em geral, há décadas vem acompanhando o aumento na demanda por alimentos, ocasionada principalmente pelo crescimento populacional contínuo. Na capital Manaus, por exemplo, verificou-se que no ano de 2010 a mesma saiu do $9^{\circ}$ para o $7^{\circ}$ lugar dentre os 10 municípios mais populosos do país, com uma população de 1.802 .525 habitantes, o que refletiu drasticamente na economia, sendo que a mesma encontrase entre as seis capitais com maior PIB do país (IBGE, 2010), demonstrando aumento substancial na produção de áreas até então pouco exploradas como o setor primário.

$\mathrm{Na}$ avicultura do Estado do Amazonas, em uma abordagem histórica, ao final da década de 1980 o segmento de corte atendia 40\% da demanda do Estado, contudo, com a importação de frango congelado oriundo das regiões Sudeste e Sul do país, essa produção foi reduzindo progressivamente até tornar-se inexpressiva. Esmiuçando esta problemática, verifica-se que devido às facilidades encontradas com o surgimento do transporte rodoviário, de logísticas apropriadas na importação de produtos comestíveis perecíveis e preços competitivos de fornecedores que já praticavam técnicas modernas de produção em larga escala de frango de corte (SANTOS, 1998; CRUZ, 2011), houve na avicultura do Amazonas a ocorrência de duas consequências importantes: a primeira é que deslocou os produtores locais para o segmento de postura, cujas peculiaridades eram mais favoráveis ao desenvolvimento local, e a mudança de hábito de consumo da população que passou a consumir o frango congelado que apresenta vantagens aparentes e facilidades de armazenamento e conservação.

Outra peculiaridade observada constantemente no setor avícola do Amazonas é relacionada ao item alimentação, onde este corresponde a, aproximadamente, 70\% do custo total de produção. Porém, apresenta um quadro extremamente desfavorável uma vez que o Estado importa $100 \%$ de todas as matérias-primas utilizadas na fabricação de rações balanceadas, principalmente oriundas do Estado do Mato Grosso (CRUZ, 2011). Mensalmente são importadas cerca de 6.000 toneladas de 
milho ao preço médio de $\mathrm{R} \$ 543,33$ a tonelada e 2.000 toneladas de farelo de soja ao preço médio de $\mathrm{R} \$ 1.350,00$ a tonelada, resultando em $\mathrm{R} \$ 5.959 .980,00 \mathrm{com}$ a importação apenas destes itens (IBGE, 2010; FAEA, 2014).

Estas matérias-primas chegam principalmente pelo município de Itacoatiara, que fica no Médio Amazonas, caracterizando-se por possuir uma infraestrutura portuária com padrão internacional, principalmente pela experiência de sucesso de escoamento da safra de soja do Mato Grosso para os mercados da Europa, Estados Unidos e Ásia, através das embarcações que saem do porto graneleiro do município. Em atividade desde 1997, esta estrutura portuária de origem privada viabilizou o Corredor Noroeste de Exportação onde é escoada a produção graneleira das regiões Noroeste de Mato Grosso e Sul de Rondônia, auxiliando também no abastecimento da atividade avícola do Estado do Amazonas como um todo devido estar no caminho da via de exportação (À CRÍTICA, 2009).

Apesar do alto custo com alimentação, o Estado do Amazonas atualmente consegue atender a cerca de 90 a $95 \%$ da sua demanda de ovos, destacando-se o município de Manaus como grande produtor (IBGE, 2012).

Segundo o Atlas do Setor Primário no Amazonas, desenvolvido pela SEPLANAM (2013), a atividade avícola mantém-se concentrada em poucos municípios (os que estão interligados por vias terrestres) e talvez seja, dentre todas as outras atividades do setor primário no Estado, a que mais tem se desenvolvido, possibilitando significativo incremento na oferta de seus produtos para a população.

A partir deste conjunto de fatores objetiva-se, com este trabalho, realizar o diagnóstico do setor avícola no Estado do Amazonas, buscando levantar dados precisos quanto aos segmentos encontrados na avicultura, sua real contribuição ao setor primário e os municípios de maior representatividade para a atividade avícola do Estado.

\section{MATERIAL E MÉTODOS}

\section{1 ÁREA DE ESTUDO E CARACTERIZAÇÃO DOS MUNICÍPIOS}

A produção avícola no Estado do Amazonas foi avaliada por regióes 
administrativas ou microrregiões, conforme a divisão territorial por microrregião adotada pelo Instituto de Desenvolvimento Agropecuário e Florestal Sustentável do Estado do Amazonas (IDAM), e considerando um período de análise e levantamentos de um ano, sendo realizado de janeiro a dezembro de 2013.

As microrregiões do Estado foram classificadas da seguinte forma: Alto Solimões (municípios de Amaturá, Atalaia do Norte, Benjamin Constant, São Paulo de Olivença, Santo Antônio do Içá, Tabatinga e Tonantins), Jutaí/Solimões/Juruá (municípios de Alvarães, Fonte Boa, Japurá, Juruá, Jutaí, Maraã, Tefé e Uarini), Purus (municípios de Boca do Acre, Canutama, Lábrea, Vila Extrema, Pauini e Tapauá), Juruá (municípios de Carauari, Eirunepé, Envira, Guajará, Ipixuna e Itamarati), Madeira (municípios de Apuí, Borba, Humaitá, Manicoré, Santo Antônio do Matupi e Novo Aripuanã), Alto Rio Negro (municípios de Barcelos, Santa Isabel do Rio Negro e São Gabriel da Cachoeira), Rio Negro/Solimões (municípios de Anamã, Anori, Autazes, Beruri, Caapiranga, Careiro, Careiro da Várzea, Coari, Codajás, Iranduba, Manacapuru, Manaquiri, Manaus, Novo Airão, Rio Preto da Eva e Vila Rica de Caviana), Médio Amazonas (municípios de Itacoatiara, Itapiranga, Maués, Nova Olinda do Norte, Novo Remanso, Presidente Figueiredo, Silves e Urucurituba) e Baixo Amazonas (municípios de Barreirinha, Boa Vista do Ramos, Nhamundá, Parintins, São Sebastião do Uatumã e Urucará).

\subsection{COLETA E ANÁLISE DOS DADOS POR MICRORREGIÃO}

Os dados desta pesquisa são oriundos de natureza primária e secundária. A pesquisa de campo foi realizada no período de janeiro a dezembro de 2013, por meio da aplicação de questionários a produtores avícolas localizados e filiados às unidades do Instituto de Desenvolvimento Agropecuário e Florestal Sustentável do Estado do Amazonas (IDAM), órgão designado como responsável pela coleta dos dados do setor primário nos municípios do Estado do Amazonas devido sua abrangência nas microrregióes e distritos do mesmo. As coletas foram executadas em todos os estabelecimentos avícolas pertencentes e sob fiscalização do município (cidades, ilhas, vilas e etc.) e posteriormente as microrregióes às quais estes pertencem. O trabalho de coleta destes dados foi executado por técnicos do IDAM em seus 
respectivos municípios, sendo posteriormente organizados, tabulados e analisados pela equipe de técnicos e profissionais do Setor de Avicultura da Faculdade de Ciências Agrárias da Universidade Federal do Amazonas (UFAM).

Como complemento, foram realizadas entrevistas com pessoas ligadas à atividade avícola no Estado (setor de propriedades rurais, instalações, fabricação de rações, produtores, técnicos e etc.), que contribuíram para ampliar o conhecimento sobre a realidade do setor. Os dados secundários foram coletados nas seguintes fontes: Instituto Brasileiro do Meio Ambiente e dos Recursos Naturais Renováveis (IBAMA), Instituto Brasileiro de Geografia e Estatística (IBGE), Federação da Agricultura e Pecuária do Estado do Amazonas (FAEA) e Associação Amazonense de Avicultura (AAA). As fontes de dados consistiram na avaliação socioeconômica com os produtores das microrregiões para identificação da produção conforme a aptidão dos animais manejados, separando-os em: postura (número de caixas de ovos em média produzidas), corte (toneladas de carne em média produzidas) e caipira (número de caixas de ovos e toneladas de carne produzidas em média). Os dados foram agrupados em sistemas de soma de produção total a partir das amostras coletadas nos questionários conforme o número de produtores por município obtendo a sua produção total conforme a aptidão e unidade e extraída sua participação para a produção total do Estado conforme metodologia adaptada das fórmulas econômicas propostas por Rossetti (2004) para obtenção de dados produtivos de uma atividade econômica em sistema de cadeia de produção.

\subsection{AVALIAÇÃO INDIVIDUAL DAS APTIDÕES PRODUTIVAS}

Neste caso, os dados foram agrupados por aptidões produtivas avaliadas em separado, ou seja, levou-se em consideração como cada microrregião participa de cada uma das aptidões produtivas individualmente. Nesta avaliação os dados oriundos do levantamento a partir da aplicação de questionário socioeconômico com todos os produtores das microrregiões foram separados em: postura (número de animais e número de criadores em média por microrregião e sua participação na produção de ovos total do Estado, por caixas de ovos produzidas), corte (análise dos dados coletados e descrição da atividade no Estado) e caipira (número de animais e 
número de criadores em média por microrregião e sua associação com a produção do Estado a partir da dupla aptidão fornecida por este sistema de criação).

\subsection{AVALIAÇÃO DA PRODUÇÃO AVÍCOLA NA CIDADE DE MANAUS}

Em razão de encontrar-se no centro da produção avícola e ponto máximo de destaque da economia do Estado do Amazonas, foi realizada avaliação da cidade de Manaus individualmente a fim de diagnosticar dados sucintos quanto à sua real participação e importância para a avicultura do Estado. Para isso, foi realizado levantamento a partir da aplicação de questionário socioeconômico em todos os estabelecimentos avícolas pertencentes ao município de Manaus, objetivando reunir os seguintes dados: plantel (número de animais por aptidão e espécie na cidade), produção de ovos diária, produção semanal de aves para corte, tipo de mão de obra utilizada (familiar, contratada e temporária) e consumo de ração por propriedade (kg/mês) codificando estes dados a partir da adaptação das fórmulas econômicas propostas por Rossetti (2004) para obtenção de dados produtivos de uma atividade econômica primária.

\section{RESULTADOS E DISCUSSÃO}

Nesta seção são apresentados dados obtidos na pesquisa para avaliação da produção avícola no Estado por microrregião. A apresentação dos dados traça um diagnóstico da produção avícola do Estado do Amazonas a partir das aptidões de cada microrregião e sua produção, conforme é demonstrado na Tabela 1.

Embora a produção de ovos geralmente não se encontre como vital para a economia na grande maioria dos Estados (DELLA GIUSTINA, 2008), esta para o Estado do Amazonas em específico merece atenção, principalmente porque possui um volume de produção expressivo perante outros Estados e por ser exercida por produtores independentes que investem cifras representativas neste visando a tecnificação e a inserção no contexto amazônico de forma sustentável (ANDERSSON et al., 2005), seguindo uma tendência da avicultura industrial como um todo (ANDERSEN et al., 2005). Além disso, o segmento de postura caracteriza-se como amplamente organizado dentro da cadeia produtiva em ciclo fechado, porém, 
atuando de forma individualizada, diferindo, portanto, da cadeia produtiva de aves de corte brasileira como um todo, a qual preza-se por um atrelamento a grandes empresas integradoras.

Esta produção do Estado fortemente direcionada à produção avícola no segmento de postura leva principalmente em consideração o volume maciço de produção de ovos diagnosticado. Segundo estudos de Sobrinho e Fonseca (2007), os fenômenos de aumentos significativos na produção avícola do Brasil como um todo, em especial na avicultura de postura, podem ser atribuídos às inovações tecnológicas que ocorreram principalmente nos últimos 30 anos, o que acrescenta fatores de competitividade ao mercado e desenvolvimento de segmentos em ascensão do setor primário como um todo.

Tabela 1. Produção avícola das microrregiões do Estado do Amazonas conforme a aptidão produtiva

\begin{tabular}{ccccc}
\hline Microrregião & Postura & Corte & $\begin{array}{c}\text { Postura } \\
\text { Caipira }\end{array}$ & Corte Caipira \\
\cline { 2 - 5 } & $\begin{array}{c}\text { Caixas de } \\
\text { ovos }\end{array}$ & $\begin{array}{c}\text { Toneladas de } \\
\text { carne }\end{array}$ & $\begin{array}{c}\text { Caixas de } \\
\text { ovos }\end{array}$ & $\begin{array}{c}\text { Toneladas de } \\
\text { carne }\end{array}$ \\
\hline Alto Rio Negro & 864,00 & 24,00 & $4.335,00$ & 28,90 \\
Alto Solimões & $10.650,00$ & 116,99 & $11.083,50$ & 73,89 \\
Baixo Amazonas & $31.335,00$ & 13,12 & $9.693,00$ & 64,62 \\
Juruá & $12.000,00$ & 7,40 & $15.442,80$ & 102,95 \\
Jutaí/Solimões/ & $4.884,00$ & 32,20 & $207.891,60$ & $1.369,82$ \\
Juruá & $5.760,00$ & 13,25 & $52.110,00$ & 347,40 \\
Madeira & $72.222,00$ & 34,25 & $27.063,00$ & 180,42 \\
Médio Amazonas & $8.730,00$ & 5,90 & $5.822,10$ & 38,81 \\
Purus & $1.177 .865,40$ & 101,25 & $45.465,30$ & 303,10 \\
Rio Negro/ & & 348,37 & $378.906,30$ & $2.509,91$ \\
\hline Solimões & $1.324 .310,40$ & & & \\
\hline Total & & & & \\
\hline
\end{tabular}

Fonte: Instituto de Desenvolvimento Agropecuário e Florestal Sustentável do Estado do Amazonas (IDAM) e Federação de Agricultura e Pecuária do Estado do Amazonas. Dados coletados no ano de 2013 e processados em 2014. 
O Estado do Amazonas adequa-se perfeitamente neste contexto. Suas limitações territoriais e dificuldades de estabelecer uma logística que possibilite escoar de forma adequada a produção animal impediram que diversas atividades do setor primário não se desenvolvessem na região ao longo do tempo. Porém, a avicultura, principalmente o segmento de postura, por estar em um patamar de desenvolvimento tecnológico acima das demais categorias e em plena ascensão conseguiu se estabelecer na região adaptando sistemas de manejo utilizados em outras regiões ao ambiente amazônico e obtendo resultados favoráveis à continuidade da atividade no Estado, como os citados por Matos et al. (2009), Carioca et al. (2010), Hanna et al. (2013), Miller et al. (2013) e Rufino et al. (2014).

A década de 1990 foi determinante para o crescimento do setor avícola na região, principalmente pela grande expansão tecnológica do setor e uma mudança na mentalidade referente à gestão da empresa rural no Estado. Foi-se criando uma cultura de expansão da profissionalização da cadeia produtiva, deixando um pouco de lado a cultura familiar e incorporando à avicultura do Estado uma tendência relacionada ao agrobusiness fortemente difundida nas demais regiões do Brasil, principalmente no Centro-Oeste, Sudeste e Sul.

Conforme a atividade de postura foi crescendo no Estado do Amazonas, naturalmente direcionou-se o foco para este segmento em questão. Na Tabela 2 são apresentados os dados obtidos para avaliação da avicultura de postura na produção avícola do Estado do Amazonas separadamente das demais aptidões produtivas, sendo classificada por microrregiões. O objetivo nesta avaliação foi de apresentar os dados que diagnosticam o comportamento da produção avícola de postura e sua representatividade para a economia do Estado.

Tabela 2. Diagnóstico do segmento de postura do setor avícola das microrregiões componentes do Estado do Amazonas

(continua)

\begin{tabular}{ccccc}
\hline Microrregião & $\begin{array}{c}\text { Número de } \\
\text { criadores }\end{array}$ & $\begin{array}{c}\text { Número de Aves } \\
\text { (Plantel) }\end{array}$ & $\begin{array}{c}\text { Produção de } \\
\text { carne (ton.) }\end{array}$ & $\begin{array}{c}\text { Produção } \\
\text { de Ovos (\%) }\end{array}$ \\
\hline Alto Rio Negro & 5 & 4.120 & 2,60 & 0,065242 \\
Alto Solimões & 46 & 15.160 & 8,41 & 0,804192 \\
Baixo Amazonas & 2 & 67.250 & 42,37 & 2,366137
\end{tabular}




\begin{tabular}{ccccc} 
Juruá & 7 & 24.500 & 15,44 & 0,906132 \\
Jutaí/Solimões/Juruá & 17 & 8.140 & 0,00 & 0,368796 \\
Madeira & 2 & 28.000 & 17,64 & 0,434943 \\
Médio Amazonas & 6 & 84.500 & 33,08 & 5,453555 \\
Purus & 8 & 17.00 & 10,71 & 0,659211 \\
Rio Negro/Solimões & 83 & 1.879 .620 & $2.945,62$ & 88,94179 \\
\hline Total & 176 & 2.111 .290 & $3.075,87$ & 100 \\
\hline
\end{tabular}

Fonte: Instituto de Desenvolvimento Agropecuário e Florestal Sustentável do Estado do Amazonas (IDAM) e Federação de Agricultura e Pecuária do Estado do Amazonas. Dados coletados no ano de 2013 e processados em 2014.

A cadeia produtiva que envolve a avicultura de postura, assim como as diversas cadeias produtivas mercantis, se constituiu apresentando características próprias em termos de produto, mercado, tecnologia, localização geográfica e organização da produção (ESPÍNDOLA, 2002), fatores que fizeram com que este setor conseguisse estabelecer-se em um cenário que até os tempos modernos apresenta inúmeras barreiras logísticas e mercantis que impedem que este cresça em um ritmo ainda maior.

A implantação e implementação do segmento de postura no Estado do Amazonas pode ser amplamente associada ainda à imigração japonesa na região, que inicialmente visava apenas servir de auxílio aos setores de horticultura e fruticultura através da produção de esterco orgânico o que acabou por fortalecer a máxima do hortifrutigranjeiro e da produção em pouco espaço territorial. Porém, devido ao crescimento populacional da região com a implantação do polo industrial de Manaus e o consequente êxodo rural, a demanda por alimentos levou o setor a direcionar seu foco à produção de ovos, principalmente por sua composição nutricional apresentar-se completa e rica em proteína (CRUZ, 2011), e um preço que possibilitasse atender as camadas de menor renda, causando uma disparada do segmento avícola de postura, além de continuar fornecendo o esterco como insumo para a produção hortifrúti e a carne das aves ao final do ciclo de produção.

A cadeia agroindustrial do ovo, assim como outras atividades agrícolas do 
Brasil, passou por problemas de cunho econômico, mais precisamente no final do ano de 1994, durante a implementação do Plano Real, quando se aumentaram os custos de produção. Porém, mesmo que em leve crise, o setor avícola de postura no Estado do Amazonas manteve o nível de desenvolvimento do segmento e estimulou os produtores a buscarem fontes de recursos para investirem em instalações mais modernas, métodos mais evoluídos de produção, de manejo e controle de sanidade que otimizassem a produção. Além disso, o referido segmento conta atualmente inclusive com o Selo de Identificação para ovos produzidos no Estado do Amazonas, com o objetivo de garantir ao consumidor um produto de maior confiabilidade com controle de qualidade e auxiliando à saúde pública por combater produtos de baixa qualidade e transmissores de patogenias (ANSELMO, 2015).

O segmento de aves de postura no Estado apresenta-se condensado, pois concentra planteis de alta densidade e produção em poucos produtores, acompanhando uma tendência que é amplamente verificada nos grandes centros produtores de ovos do país, considerando a distribuição que é observada em outros Estados como Espírito Santo e o Estado de São Paulo (INCAPER, 2003), o que coloca o Estado do Amazonas, mais precisamente o município de Manaus e região metropolitana (municípios que formam a microrregião Rio Negro/Solimões), em patamares de produção equiparados aos grandes centros da cadeia de produção de ovos.

Porém, mesmo com esse desenvolvimento acentuado e produção expressiva, o setor ainda possui gargalos a serem resolvidos, que entre os principais são: os problemas com fornecimento de energia e causas ambientais (que inviabilizam a aprovação de projetos de crédito rural), falta de laboratórios especializados em análises patológicas e nutricionais, custos de produção com insumos, deficiência de assistência técnica pública, infraestrutura de armazenagem de grãos inapropriada, acesso ao mercado de insumos na safra, falta de políticas públicas que incentivem o produtor dentre outros (FAEA, 2014).

A avicultura de corte no Estado, em contrapartida à avicultura de postura, apresenta-se pouco desenvolvida, com uma produção inexpressiva comparando-se com a média de produção de outros Estados ou mesmo com a sua contribuição para a média nacional, que se caracteriza por uma das cadeias produtivas brasileiras com maior nível de coordenação, conferindo-lhe grande competitividade no mercado 
mundial (CARLETTI FILHO, 2005).

Outros fatores que contribuíram para este pífio desenvolvimento da avicultura de corte foi o alto custo das matérias-primas utilizadas na fabricação de rações que, segundo afirmaram Loureiro et al. (2007), em determinadas épocas do ano estes podem chegar a atingir $80 \%$ do custo total, e a ausência de incubatórios e abatedouros adequados para processamento do produto final. Estes acabam por desestimular o produtor a investir neste segmento devido à total incompatibilidade do preço do animal produzido na região com o preço praticado pelo mercado nacional, mesmo contabilizando os entraves de logística que naturalmente encarecem o produto importado de outras regiões. Togashi (2000), por exemplo, afirmou justamente que algumas regiões do Brasil são prejudicadas pela baixa disponibilidade de grãos, evidenciando esta máxima encontrada principalmente na região Norte do país.

A partir deste contexto caracterizado no Estado, de restrição de recursos e alto valor de matérias-primas, as pesquisas com alimentos alternativos em rações para aves têm buscado minimizar os custos de produção, principalmente com alimentação, tendo em vista a fatia que estes representam nos custos totais de produção (RUFINO et al., 2015). E, em pesquisas com ingredientes alternativos para aves, a análise econômica dos resultados experimentais provou-se essencial, uma vez que produtores e especialistas disporão de critérios que irão contribuir para utilização dos mesmos de forma mais cautelosa (SILVA et al., 2009), e podem impulsionar o agronegócio local, com sistemas de integração de culturas como é praticado em Estados com maior tradição agrícola. Porém, os resultados obtidos ainda demonstram-se preliminares ou ainda sem aplicação em escalas industriais e que possam viabilizar de forma significativa o decréscimo do preço do frango.

Segundo Freitas e Bertoglio (2001), e Garcia (2004), uma característica da produção avícola de corte que a diferencia de outras atividades agropecuárias são as relações existentes entre a unidade produtiva e a indústria, principalmente em sistemas de integração como os atuantes no Sul do País (Rio Grande do Sul, Santa Catarina e Paraná), onde a integração se dá por meio de contratos. O produtor recebe o pinto de um dia, responsabilizando-se pelo manejo de engorda e, quando o frango atinge a fase adulta, entrega-o para a empresa integradora (frigorífico), que abate, processa e comercializa o produto. Este método favorece a empresa 
integradora, pois elimina grande parte do risco existente, sem perder o controle em todas as etapas produtivas. Se formos aplicar estes mesmos conceitos na região Norte como um todo, acaba-se por verificar significativas incompatibilidades ao modelo de produção avícola praticado na mesma, que preza por independência nos sistemas de produção e investimentos próprios para obtenção de tecnologias produtivas, além de possuir dificuldades para escoamento do produto final a um preço competitivo.

Na Tabela 3, em contrapartida, são apresentados os dados obtidos na pesquisa para avaliação da avicultura caipira de dupla aptidão no Estado do Amazonas, que demonstram que a denominada atividade avícola (também denominada como alternativa) há tempos já deixou de ser uma atividade meramente direcionada para a subsistência em comunidades ribeirinhas e/ou familiares dentro dos Sistemas Agroflorestais no Estado do Amazonas. Porém, isso não significa que tenha deixado de estar associada à agricultura familiar, pelo contrário, o que realmente tem acontecido é um aumento substancial da demanda e da produção de carne e ovos de aves manejadas no sistema caipira, especialmente pela propensão do mercado por produtos de origem animal que além de trabalharem a parte técnica produtiva também obedeçam à normativa agropecuária sustentável (MAZZUCO, 2008).

Tabela 3. Diagnóstico da avicultura caipira de dupla aptidão nas microrregiões componentes do Estado do Amazonas

\begin{tabular}{ccccc}
\hline Microrregião & $\begin{array}{c}\text { Número de } \\
\text { criadores }\end{array}$ & $\begin{array}{c}\text { Número de Aves } \\
\text { (Plantel) }\end{array}$ & $\begin{array}{c}\text { Produção de } \\
\text { carne (\%) }\end{array}$ & $\begin{array}{c}\text { Produção de } \\
\text { Ovos (\%) }\end{array}$ \\
\hline Alto Rio Negro & 66 & 7.643 & 1,144082 & 1,151436 \\
Alto Solimões & 1.908 & 94.944 & 2,92513 & 2,94393 \\
Baixo Amazonas & 438 & 277.375 & 2,558152 & 2,574594 \\
Juruá & 2.085 & 52.134 & 4,075625 & 4,101741 \\
Jutaí/Solimões/Juruá & 4.613 & 58.360 & 54,86623 & 54,57646 \\
Madeira & 3.086 & 159.950 & 13,75274 & 13,84113 \\
Médio Amazonas & 2.013 & 92.370 & 7,142399 & 7,188306 \\
Purus & 860 & 20.745 & 1,536554 & 1,546271 \\
Rio Negro/Solimões & 4.806 & 237.743 & 11,99909 & 12,07613 \\
\hline Total & 19.876 & 1.001 .264 & 100 & 100 \\
\hline
\end{tabular}

Fonte: Instituto de Desenvolvimento Agropecuário e Florestal Sustentável do Estado do Amazonas (IDAM). Dados coletados no ano de 2013 e processados em 2014. 
Apesar de não possuir a intenção direta de competir com a avicultura industrial, a avicultura caipira apresenta um grande potencial como componente para estruturar o desenvolvimento do mercado local (FRAXE et al., 2007), principalmente pela excelente aceitação que o produto "frango caipira" tem no mercado amazonense, a excelente adaptabilidade das aves à condição amazônica e 0 déficit de carne de frango que se possui no mercado da economia estadual devido ao fraco e quase inexistente desenvolvimento da avicultura de corte no mesmo.

O trabalho de difusão tecnológica que instituições de pesquisa e extensão têm realizado nas comunidades de produção familiar, como as desenvolvidas pela Universidade Federal do Amazonas (CRUZ et al., 2013; AVIMAZON, 2015), foram determinantes para o crescimento significativo e acentuado da avicultura caipira no Estado do Amazonas, destacando o aspecto produtivo devido aos números obtidos, como a produção de 2.509,91 toneladas de carne de frango caipira, produção aproximadamente oito vezes maior em relação à avicultura de corte no referido Estado.

Além disso, a avicultura caipira enquadrou-se perfeitamente no contexto amazônico de produção sustentável, cultura amplamente difundida para preservação de recursos naturais (CASTRO, 2009). É importante destacar que o desenvolvimento sustentável também implica equidade social, que se fundamenta no comprometimento e no respeito por direitos fundamentais como acesso aos programas de inclusão social e geração de renda (ANDRADE, 2007; RIBEIRO et al., 2004), havendo um equilíbrio entre consumo e produção, modelo este adotado continuamente nas unidades de produção sustentável e/ou familiar (GALVÃO et al., 2005). A produção avícola caipira no Estado pouco está relacionada com a microrregião Rio Negro/Solimões onde há extensa concentração urbana, sendo assim, os municípios do interior do Estado do Amazonas, principalmente os da microrregião Jutaí/Solimões/Juruá que representam mais da metade da produção de carne de frango caipira, desenvolveram a avicultura caipira de forma extensa o que alavancou o setor a patamares extremamente competitivos com outros segmentos de produção de carne no Estado. Verifica-se ainda que microrregiões com planteis acentuados não possuem participação significativa na produção de carne e ovos caipiras do Estado, evidenciando de certa forma uma influência da agricultura familiar e de subsistência ainda presentes no sistema de produção. 
A partir de todo o contexto da avicultura no Estado do Amazonas evidenciado, verifica-se uma alta concentração da produção avícola na microrregião Rio Negro/Solimões, que engloba principalmente o município de Manaus e região metropolitana onde concentra-se mais da metade de todo o recurso financeiro produzido no Estado. Sendo assim, realizou-se uma avaliação em separado do município de Manaus e região metropolitana buscando verificar qual a real participação destes para a produção estadual como um todo (Tabela 4).

Tabela 4. Avaliação da composição do setor avícola no município de Manaus

\begin{tabular}{lc}
\hline Variável & Dados coletados \\
\hline Plantel de aves de postura & 1.353 .969 aves \\
Plantel de aves de corte & - \\
Plantel de aves para destinação caipira & 16.071 aves \\
Produção diária de ovos & 777.509 unidades \\
Produção semanal de aves & 2.352 aves \\
Pessoas envolvidas na produção avícola & 432 pessoas \\
Mão de obra familiar & $32 \%$ dos funcionários \\
Mão de obra contratada & $63 \%$ dos funcionários \\
Mão de obra temporária & $5 \%$ dos funcionários \\
\hline Total de ração consumida por mês & 7.419 .249 quilos de ração \\
\hline
\end{tabular}

Fonte: Instituto de Desenvolvimento Agropecuário e Florestal Sustentável do Estado do Amazonas (IDAM) e Federação de Agricultura e Pecuária do Estado do Amazonas. Dados coletados no ano de 2013 e processados em 2014.

O município de Manaus, regendo a tendência encontrada no Estado, concentra sua produção avícola quase que totalmente no segmento de postura, tendo em vista os inúmeros fatores citados anteriormente que contribuíram para 0 crescimento populacional e a consequente demanda por alimentos a baixo custo, principalmente após a implantação da Zona Franca no Polo Industrial de Manaus.

Vale ressaltar também o papel de destaque que a mesma possui para produção de ovos nacional, obtendo rendimentos de produção que se encontram entre os maiores do país há muitos anos (Tabela 5), equiparando-se aos grandes centros nacionais produtores de ovos. 
O crescimento deste segmento viabilizou e ao mesmo tempo acompanhou uma tendência do mercado de produção de ovos no Brasil com a profissionalização e tecnificação da mão de obra, onde verifica-se que apenas 32\% desta é de cunho familiar.

Tabela 5. Relação dos principais municípios produtores de ovos no Brasil no período de 2008 a 2012

\begin{tabular}{cccccc}
\hline \multirow{2}{*}{ Município } & \multicolumn{5}{c}{ Produção anual (milhões de dúzias) } \\
\cline { 2 - 6 } & $\mathbf{2 0 0 8}$ & $\mathbf{2 0 0 9}$ & $\mathbf{2 0 1 0}$ & $\mathbf{2 0 1 1}$ & $\mathbf{2 0 1 2}$ \\
\hline Bastos (SP) & 193,674 & 202,419 & 213,851 & 226,026 & 235,863 \\
\hline Sta. Maria do Jetibá (ES) & 118,100 & 151,842 & 154,100 & 153,652 & 175,420 \\
\hline Itanhandu (MG) & 79,961 & 81,789 & 81,970 & 84,094 & 94,124 \\
\hline Manaus (AM) & 41,512 & 53,340 & 53,340 & 56,005 & 50,000 \\
\hline Tupã (SP) & 34,385 & 34,908 & 34,975 & 40,691 & 41,350 \\
\hline Inhumas (GO) & 27,000 & 28,240 & 32,215 & 35,313 & 39,680 \\
\hline Guararapes (SP) & 37,197 & 37,777 & 40,680 & 35,981 & 36,966 \\
\hline
\end{tabular}

Fonte: Instituto Brasileiro de Geografia e Estatística (IBGE) - Produção Pecuária Municipal (2008 2012).

O mercado avícola manauara incorporou-se ao contexto brasileiro de agronegócio em escala industrial, mesmo que para atender apenas à demanda do Estado devido ao isolamento geográfico do mesmo. Além disso, verifica-se que o plantel de aves de postura neste corresponde a mais da metade tanto do plantel encontrado na microrregião pertencente quanto ao plantel de todo o Estado, evidenciando uma concentração da atividade avícola no município e sua importância para o setor como um todo.

\section{CONSIDERAÇÕES FINAIS}

O Estado do Amazonas possui forte inclinação de sua produção avícola direcionada para o segmento de postura, atividade esta amplamente desenvolvida na 
região, principalmente na microrregião do Rio Negro/Solimões, sendo o município de Manaus (capital do Estado) e regiões metropolitanas (municípios próximos e interligados por via terrestre) responsáveis por extensa fatia desta produção. A avicultura de corte, em contrapartida, praticamente inexiste no Estado, sendo esta lacuna preenchida pela ascensão da avicultura caipira, atividade que não apenas compõe as estatísticas, mas possui participação efetiva na economia do Estado tanto por seu volume de produção quanto pelo contexto social e agroecológico do sistema de manejo caipira.

\section{AGRADECIMENTOS}

Ao Instituto de Desenvolvimento Agropecuário e Florestal Sustentável do Estado do Amazonas (IDAM) pela cessão dos dados.

\section{REFERÊNCIAS}

A CRÍTICA. Agricultura familiar precisa de incentivos, 2009. Disponível em: < http:// acritica.uol.com.br/especiais/Agriculturafamiliarprecisaincentivos_0_296970308. html > . Acesso em: 09 abr. 2015.

ANDERSEN, H. J.; OKSBJERG, N.; THERKILDSEN, M. Potential quality control tools in the production of fresh pork, beef and lamb demanded by the European society. Livestock Production, v. 94, p. 105-124, 2005.

ANDERSSON, R.; ALGERS, B.; BERGSTRON, L.; LUNDSTRON, K.; NYBRANT, T.; SJODEN, P. O. Food 21: A research program looking for measures and tools to increase food chain sustainability. Ambio, v. 34, p. 275-282, 2005.

ANDRADE, A. L. M. Indicadores de sustentabilidade da reserva de desenvolvimento sustentável do piranha, Manacapuru, Amazonas, Brasil. Acta Amazonica, v. 37, p. 401-412, 2007. 
ANSELMO, L. Selo de identificação garante qualidade de ovos do Amazonas. 2015. Disponível em: < http://acritica.uol.com.br/noticias/manausamazonasamazoniaSeloidentificacaogarantequalidadeovosAmazonas_0_1335466444.html $>$. Acesso em: 08 abr. 2015.

AVIMAZON. Projetos de avicultura familiar desenvolvidos no Estado do Amazonas. 2015. Disponível em: < http://www.avimazon.ufam.edu.br/index.php/extensao/projetos-de-extensao>. Acesso em: 01 mai. 2015.

BRAGA, C. V. P. et al. Efeito da inclusão do Farelo de coco em rações para poedeiras comerciais. Revista Brasileira de Zootecnia, v. 34, n. 1, p. 76-80, 2005.

CARIOCA, S. T. et al. Influência dos níveis energéticos e proteicos em rações de poedeiras leves em Manaus. Archivos de Zootecnia, v. 59, p. 455-463, 2010.

CARLETTI FILHO, P. T. Divisão de custos e alimento estratégico de uma cadeia de suprimentos integrada verticalmente: o caso do frango brasileiro. 2005. 174f. Dissertação (Mestrado em Economia Aplicada) - Escola Superior de Agricultura "Luiz de Queiroz" da Universidade de São Paulo, Piracicaba, 2005.

CASTRO, A. P. Os sistemas agroflorestais como alternativa de sustentabilidade em ecossistemas de várzea no Amazonas. Acta Amazônica, v. 39, p. 279-288, 2009.

CRUZ, F. G. G. Avicultura caipira na Amazônia. Manaus: EDUA, 2011, 80p.

CRUZ, F. G. G. Fruto do dendê pode ser utilizado em ração de aves poedeiras. Rede Diário de Comunicação, 2011. Amazônia/Ciência. Disponível em: < http://new. d24am.com/amazonia/ciencia/fruto-do-dende-pode-ser-utilizado-em-racao-de-avespoedeiras-diz-estudo/14381>. Acesso em: 02 abr. 2015.

CRUZ, F. G. G.; CHAGAS, E. O.; BOTELHO, T. R. P. Avicultura familiar como alternativa de desenvolvimento sustentável em comunidades ribeirinhas do Amazonas. Revista Interações, v. 14, n. 2, p. 197-202, 2013.

DELLA GIUSTINA, J. E. Informe Conjuntural: ovos - produção em Santa Catarina, 2003. Disponível em: < http://www.epagri.rct-sc.br> Acesso em: 12 abr. 2015. 
ESPÍNDOLA, C. J. As agroindústrias de carnes do Sul do Brasil. 2002. 274f. Tese (Doutorado) - Universidade de São Paulo, 2002.

FAEA. Federação da Agricultura e Pecuária do Estado do Amazonas. Relatório da Avicultura de Postura Comercial no Amazonas. Amazonas: FAEZ, 2014. (Relatório Técnico, 2014). 18p.

FRAXE, T. J. P. et al. Comunidades ribeirinhas amazônicas: modos de vida e uso dos recursos naturais. Manaus: EDUA, 2007, 223p.

GALVÃO, E. et al. Análise da renda e da mão-de-obra nas unidades agrícolas familiares da comunidade Nova Colônia, município de Capitão Poço, Pará. Amazônia: Ciência e Desenvolvimento, v. 1, n. 1, 2005.

GARCIA, L. A. F. Economias de escala na produção de frangos de corte no Brasil. Piracicaba. 2004. 114f. Tese (Doutorado em Economia Aplicada) - Escola Superior de Agricultura "Luiz de Queiroz" da Universidade de São Paulo, 2004.

HANNA, A. C. S. et al. Bioefficacy of the copaiba oil (Copaifera sp.) in diets of laying hens in the second production cycle in humid tropical climate. International Journal of Poultry Science, v. 12, p. 647-652, 2013.

IBGE. Instituto Brasileiro de Geografia e Estatística. Censo Demográfico de 2010, 2012. Disponível em: < http://www.censo2010.ibge.gov.br > Acesso em: 03 maio 2015.

IBGE. Instituto Brasileiro de Geografia e Estatística. Produto interno bruto dos municípios 2010-2013. 2013. Disponível em: $<$ http://www.ibge.gov.br $>$. Acesso em: 02 maio 2015.

INCAPER. Instituto Capixaba de Pesquisa. Plano estratégico de desenvolvimento da agricultura capixaba (PEDEAG). Vitória: Incaper, 2003. 275p.

LOUREIRO, R. R. S. et al. Farelo de tomate (Lycopersicum esculentum Mill.) na alimentação de poedeiras comerciais. Acta Scientiarum Animal Science, v. 29, n. 4, p. 387-394, 2007. 
MATOS, P. G. J. et al. Avaliação de Programa de Iluminação Sobre o Desempenho de Carcaça de Frangos de Corte aos 45 dias de Idade. Revista Brasileira de Nutrição Animal, v. 3, p. 1-14, 2009.

MAZZUCO, H. Ações sustentáveis na produção de ovos. Revista Brasileira de Zootecnia, v. 37, suplemento especial, p. 230-238, 2008.

MILLER, W. M. P. et al. Farinha do resíduo de tucumã (Astrocaryum vulgare Mart.) na alimentação de poedeiras. Revista Acadêmica: Ciências Agrárias e Ambientais (PUCPR. Impresso), v. 11, p. 105-114, 2013.

PEREIRA, S. C. F. Gerenciamento de cadeias de suprimentos: análise da avaliação de desempenho de uma cadeia de carne e produtos industrializados de frango no Brasil. 2003. 356f. Tese (Doutorado em Economia) - Escola de Administração de Empresas de São Paulo, Fundação Getúlio Vargas. São Paulo, FGV, 2003.

RIBEIRO, R. N. S.; TOURINHO, M. M.; SANTANA, A. C. Avaliação da sustentabilidade agroambiental de unidades produtivas agroflorestais em várzeas flúvio-marinhas de Cametá - Pará. Acta Amazônica, v. 34, p. 359-374, 2004.

ROSSETTI, J. P. Introdução à economia. 4. ed. São Paulo: Atlas, 2004.

RUFINO, J. P. F.; CRUZ, F. G. G.; MILLER, W. P. M.; MELO, R. D.; FEIJÓ, J. C.; CHAGAS, E. O. Análise econômica da inclusão de farinha do resíduo de tucumã (Astrocaryum vulgare, Mart) na alimentação de poedeiras comerciais. Revista Brasileira de Saúde e Produção Animal, v. 16, n. 1, p. 1-9, 2015.

RUFINO, J. P. F. et al. Processos de incubação artificial associados à aplicação de diferentes métodos reprodutivos em matrizes semipesadas. Revista Brasileira de Saúde e Produção Animal, v. 15, p. 765-773, 2014.

SANTOS, R. A. O. Criação de frango caipira para corte no sistema de integração. Brasília: SEBRAE/DF, 1998. 68p.

SEPLAN-AM. Secretaria de Estado de Planejamento e Desenvolvimento Econômico. Atlas do setor primário no Amazonas. p. 47, 2013. 
SILVA, E. P.; RABELLO, C. B. V.; JÚNIOR, W. M. D.; LOUREIRO, R. R. S.; GUIMARÃES, A. A. S.; LIMA, M. B.; ARRUDA, E. M. F.; BARBOSALIMA, R. Análise econômica da inclusão dos resíduos de goiaba e tomate na ração de poedeiras comerciais. Revista Brasileira de Saúde e Produção Animal, v. 10, n. 4, p. 774-785, 2009.

SOBRINHO, J. K.; FONSECA, R. A. Análise econômica da produção de ovos de galinhas poedeiras no município de Toledo (PR). Revista Eletrônica Lato Sensu, v. 2, n. 1, p. 1-20, 2007.

TOGASHI, C. K. Exigências de metionina para poedeiras de ovos marrons alimentadas com rações contendo levedura de cana de açúcar. Revista da Sociedade Brasileira de Zootecnia, v. 25, n. 4, p. 35-38, 2000.

Recebido: 16 de julbo de 2015 Aceito: 17 de setembro de 2015 